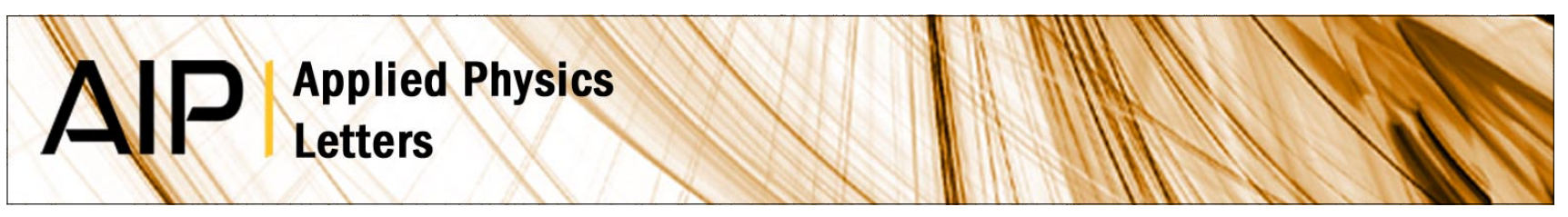

\title{
Magnetically uniform and tunable Janus particles
}

Irene Sinn, Paivo Kinnunen, Shao Ning Pei, Roy Clarke, Brandon H. McNaughton et al.

Citation: Appl. Phys. Lett. 98, 024101 (2011); doi: 10.1063/1.3541876

View online: http://dx.doi.org/10.1063/1.3541876

View Table of Contents: http://apl.aip.org/resource/1/APPLAB/v98/i2

Published by the AIP Publishing LLC.

\section{Additional information on Appl. Phys. Lett.}

Journal Homepage: http://apl.aip.org/

Journal Information: http://apl.aip.org/about/about_the_journal

Top downloads: http://apl.aip.org/features/most_downloaded

Information for Authors: http://apl.aip.org/authors

\section{ADVERTISEMENT}
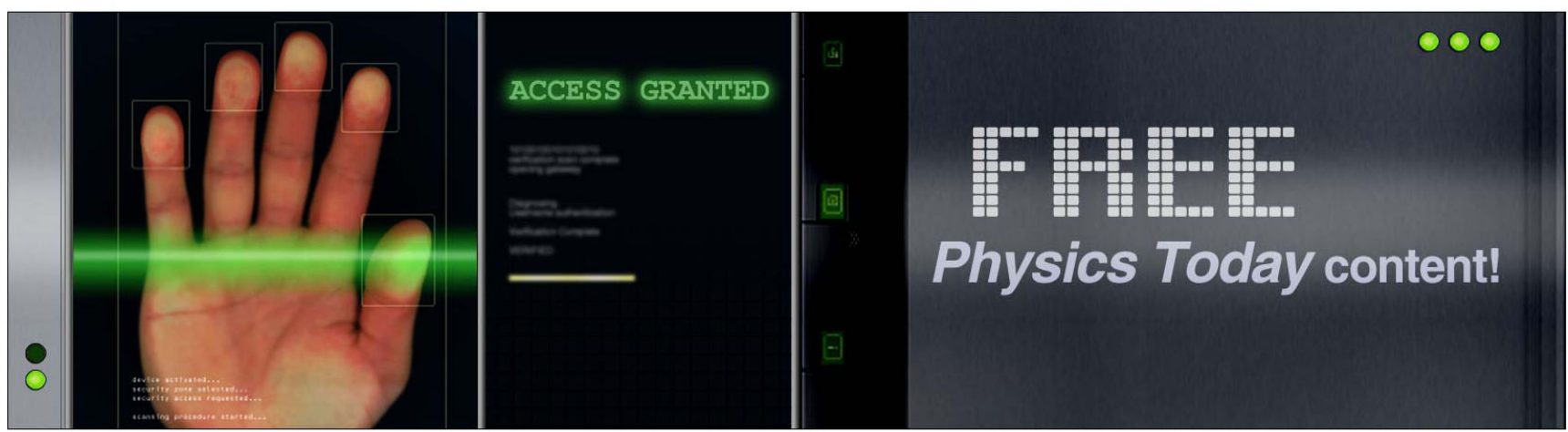


\title{
Magnetically uniform and tunable Janus particles
}

\author{
Irene Sinn, ${ }^{1,2}$ Paivo Kinnunen, ${ }^{1,3}$ Shao Ning Pei, ${ }^{1}$ Roy Clarke, ${ }^{3}$ \\ Brandon H. McNaughton, ${ }^{1,2,3, a)}$ and Raoul Kopelman 1,2,3,a),b) \\ ${ }^{1}$ Department of Chemistry, The University of Michigan, 930 North University, Ann Arbor, \\ Michigan 48109-1055, USA \\ ${ }^{2}$ Department of Biomedical Engineering, The University of Michigan, 2200 Bonisteel, Ann Arbor, \\ Michigan 48109-2099, USA \\ ${ }^{3}$ Applied Physics Program, 2477 Randall Laboratory, The University of Michigan, Ann Arbor, \\ Michigan 48109-1120, USA
}

(Received 13 May 2010; accepted 21 December 2010; published online 13 January 2011)

\begin{abstract}
Magnetic particles serve as an important tool for a variety of biomedical applications but often lack uniformity in their magnetic responsiveness. For quantitative analysis studies, magnetic particles should ideally be monodisperse and possess uniform magnetic properties. Here we fabricate magnetically uniform Janus particles with tunable magnetic properties using a spin-coating and thermal evaporation method. The resulting $2 \mu \mathrm{m}$ ferromagnetic particles exhibited a $4 \%$ magnetic response variability, and the $10 \mu \mathrm{m}$ ferromagnetic particles exhibited a $1 \%$ size variability and an $8 \%$ magnetic response variability. Furthermore, by reducing the film thickness, the particle behavior was tuned from ferromagnetic to superparamagnetic. (C) 2011 American Institute of Physics.

[doi:10.1063/1.3541876]
\end{abstract}

Magnetic particles are used extensively in biomedicine and biophysical research. The ability to manipulate functionalized magnetic particles with external magnetic fields is advantageous for applications such as whole cell and biomolecular separation, ${ }^{1}$ magnetic resonance imaging contrast agents, ${ }^{2}$ targeted drug delivery, ${ }^{3}$ and immunoassays. ${ }^{1}$ Methods used to fabricate magnetic particles or scaffolds include loading magnetic material within a nonmagnetic matrix, ${ }^{4,5}$ depositing magnetic material onto nonmagnetic particles, ${ }^{6-8}$ and polymerizing magnetic bead hydrogels using microfluidic droplet technology. ${ }^{9,10}$ While magnetic particles serve as a ubiquitous and important tool, they often lack uniformity in magnetic responsiveness. Indeed, numerous magnetic particles have been reported to have a 30 to $80 \%$ variation in magnetophoretic mobility. ${ }^{11}$ Morphological and magnetic content uniformity are important parameters for quantitative analysis methods, such as magnetoresistive sensors $^{12,13}$ and asynchronous magnetic bead rotation (AMBR) biosensors. ${ }^{14-20}$ To improve the quality and reproducibility of quantitative studies, particles should ideally be monodisperse $^{12}$ and possess uniform magnetic properties. ${ }^{21}$

In this letter, we report on the fabrication and characterization of magnetically uniform Janus particles with tunable magnetic properties using a combined method of spin coating and thermal evaporation of nickel (Ni). The fabricated magnetic Janus particles, which are characterized by the AMBR method ${ }^{5,14-16}$ and with a DC superconducting quantum interference device (SQUID), possess greater particleto-particle magnetic uniformity than previously reported particles. ${ }^{11}$ In addition, the particles' magnetic behavior may be tuned by adjusting the magnetic coating thickness to be above or below the reported $8 \mathrm{~nm}$ superparamagnetic (SPM) limit for $\mathrm{Ni}^{22}$ The $2 \mu \mathrm{m}$ diameter polystyrene particles coated with $60 \mathrm{~nm} \mathrm{Ni}$ and the $10 \mu \mathrm{m}$ diameter particles

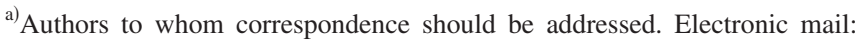
bmcnaugh@umich.edu

${ }^{b)}$ Electronic mail: kopelman@umich.edu.
}

coated with $300 \mathrm{~nm} \mathrm{Ni}$, thickness values well above the SPM limit, behaved largely ferromagnetic, with a small SPM component. The same $2 \mu \mathrm{m}$ and $10 \mu \mathrm{m}$ diameter polystyrene particles that were coated with a Ni layer below the SPM limit, $5 \mathrm{~nm}$ Ni layer and a $20 \mathrm{~nm}$ Au layer, exhibited SPM behavior.

The magnetic Janus particles were fabricated by spincoating a disordered monolayer of National Institute of Standards and Technology (NIST) approved size standard (Polysciences, Inc.) polystyrene particles onto a wafer and by thermally evaporating $\mathrm{Ni}$ onto the wafer (see Fig. 1). The evaporation technique has been previously demonstrated in the fabrication of magnetic and nonmagnetic Janus particles. ${ }^{6-8,23}$ The ferromagnetic particles were fabricated by evaporating $30 \mathrm{~nm} \mathrm{Ni}$ on $1 \mu \mathrm{m}$ particles, $60 \mathrm{~nm} \mathrm{Ni}$ on $2 \mu \mathrm{m}$ particles, $300 \mathrm{~nm} \mathrm{Ni}$ on $10 \mu \mathrm{m}$ particles, and $300 \mathrm{~nm}$ $\mathrm{Ni}$ on $100 \mu \mathrm{m}$ particles. The SPM particles were fabricated by sequentially evaporating $5 \mathrm{~nm} \mathrm{Ni}$ and $20 \mathrm{~nm} \mathrm{Au}$ onto both the $2 \mu \mathrm{m}$ and $10 \mu \mathrm{m}$ diameter particles. The Au coating was to aid in the visualization of the particles (and for potential biochemical functionalization). After fabrication, the particles were magnetized in a $60 \mathrm{mT}$ magnetic field. In depth details of the fabrication process can be found in the

(a) Suspend particles in methanol (b) Spin-coat particles onto wafer

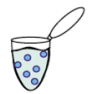
magnetic material

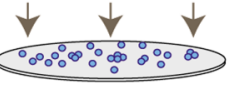

(e) Gently brush off and collect the coated particles

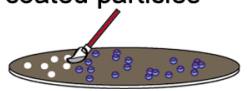

(c) Coat with evaporated

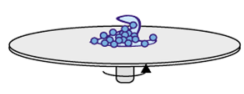

(d) Magnetize particles

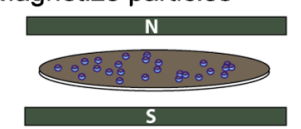

(f) Re-suspend Janus particles



FIG. 1. (Color online) Fabrication schematic for magnetic Janus particles. 


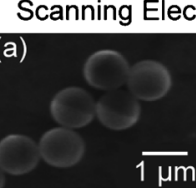

$1 \mu \mathrm{m}(30 \mathrm{~nm} \mathrm{Ni})$
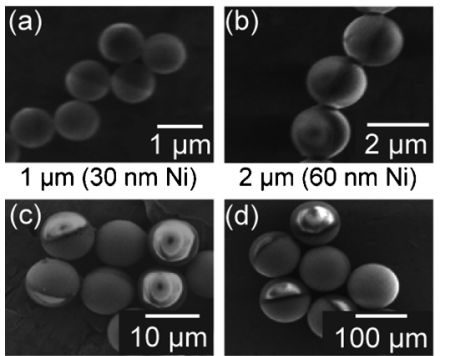

$2 \mu \mathrm{m}(60 \mathrm{~nm} \mathrm{Ni})$



$10 \mu \mathrm{m}(300 \mathrm{~nm} \mathrm{Ni})$

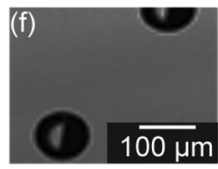

$10 \mu \mathrm{m}(300 \mathrm{~nm} \mathrm{Ni}) 100 \mu \mathrm{m}(300 \mathrm{~nm} \mathrm{Ni}) 100 \mu \mathrm{m}(300 \mathrm{~nm} \mathrm{Ni})$

FIG. 2. [(a)-(d)] SEM images and [(e) and (f)] light microscopy images of magnetic Janus particles. The particle size and corresponding Ni coating thickness are stated below each figure.

supplementary material. Up to a calculated value of $10^{9} \mathrm{mag}$ netic Janus particles ( $2 \mu \mathrm{m}$ diameter) can be fabricated on a single 4 " wafer, assuming 50\% area coverage. The ferromagnetic particles were imaged using scanning electron microscopy (SEM) and light microscopy, as shown in Fig. 2.

For AMBR analysis, a magnetic particle is placed within a rotating magnetic field and the particle's rotational response is measured. ${ }^{15,17}$ In depth details of the experimental setup can be found in Ref. 30. The particle rotates either synchronously or asynchronously with the external rotating magnetic field, depending on factors, such as the driving field frequency and the particle's magnetic properties. ${ }^{14}$ Above the critical frequency, i.e., in the asynchronous regime, the average rotational rate of the magnetic particle, can be expressed as $\langle\dot{\theta}\rangle=\Omega-\sqrt{\Omega^{2}-\Omega_{c}^{2}}, 14,24$ where $\langle\dot{\theta}\rangle$ is the average rotation frequency of the magnetic bead (in radians per second), $\Omega$ is the driving frequency, and $\Omega_{c}$ is the critical frequency. The critical frequency at which the particle becomes asynchronous is $\Omega_{c}=m B / \kappa \eta V,{ }^{5,14,24}$ where $m$ is the magnetic moment, $B$ is the amplitude of the magnetic field, $\kappa$ is the shape factor, $\eta$ is the dynamic viscosity, and $V$ is the volume of the magnetic bead. The asynchronous rotational response provides information regarding the particle's magnetic behavior; subsequently, the magnetic moment of individual particles can be determined with

$$
m=\left(\frac{\kappa \eta V}{B}\right) \Omega_{c} .
$$

For SQUID analysis, hysteresis curves of particle suspensions were obtained at a temperature below freezing (at 250 $\mathrm{K})$ to eliminate the rotational degrees of freedom. A zero field-cooled and field cooled (ZFC/FC) analysis was performed at 300 Oe magnetic field for the $2 \mu \mathrm{m}$ SPM particles.

The evaporated magnetic layer was found not to contribute significantly to the variability in magnetic response and particle size. The magnetic variability due to the initial size distribution of the polystyrene spheres was estimated using Eq. (1). The reported $1 \%$ coefficient of variation (CV) in diameter for NIST particles was calculated to affect the measured magnetic variability by up to $6 \%$ for the $2 \mu \mathrm{m}$ ferromagnetic particles and $8 \%$ for the $10 \mu \mathrm{m}$ ferromagnetic particles. Light microscopy image analysis shows that the CV in diameter for $10 \mu \mathrm{m}$ ferromagnetic particles after coating is $1 \%(10.2 \pm 0.12 \mu \mathrm{m})$, which is consistent with the reported $\mathrm{CV}$ in diameter of the NIST particles. This indicates that the variability in magnetic response and size predominantly arises from the size distribution of the initial particles.

The magnetic properties and uniformity of the $2 \mu \mathrm{m}$ ferromagnetic particles were characterized by AMBR and with a SQUID. Figure 3(a) shows light microscopy images of a $2 \mu \mathrm{m}$ Janus particle rotating synchronously with a $5 \mathrm{~Hz}$ magnetic field. When the particle was placed in a rotating magnetic field at frequencies up to $1 \mathrm{kHz}$, the rotational behavior was ferromagnetic, as shown in Fig. 3(b). ${ }^{14}$ The magnetic particle-to-particle uniformity as well as the magnetic moment was estimated with Eq. (1). ${ }^{14}$ The rotational response of $502 \mu \mathrm{m}$ ferromagnetic particles was measured to have an average critical frequency of $116 \pm 9.6 \mathrm{~Hz}$, which corresponds to an $8 \% \mathrm{CV}$ in the magnetic responsiveness. The magnetic moment of a single $2 \mu \mathrm{m}$ ferromagnetic particle was calculated to be $(1.83 \pm 0.15) \times 10^{-14} \mathrm{Am}^{2}$, provided $\eta=1 \mathrm{mPa} \mathrm{s}, \kappa=6$, and $\mathrm{B}=1 \mathrm{mT}$. From the SQUID analysis, the presence of coercivity $(75 \mathrm{Oe})$ in hysteresis loop measurements also indicates that the particles are indeed ferromagnetic [see Fig. 3(c)]. However, the magnetization saturated above 2000 Oe although the hysteresis loop closed at

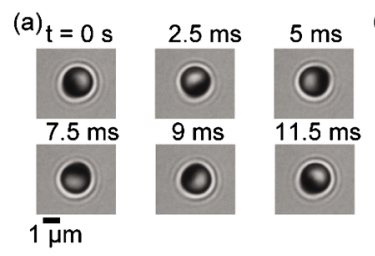

(d)



(b)

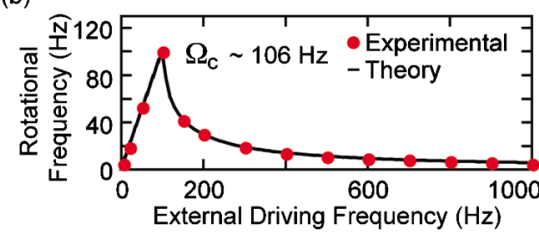

(e)

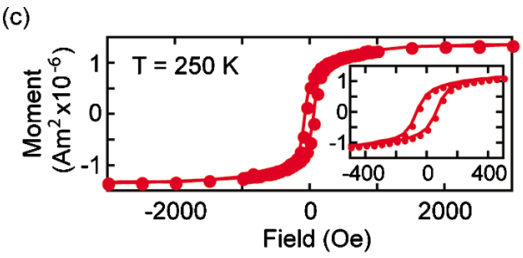

(f)

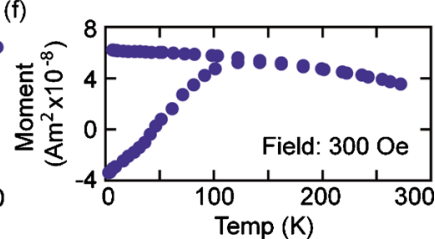

FIG. 3. (Color online) Characterization of the $2 \mu \mathrm{m}$ ferromagnetic particles (60 nm Ni coating) [(a)-(c)] and $2 \mu \mathrm{m}$ SPM particles $(5 \mathrm{~nm}$ Ni and $20 \mathrm{~nm}$ Au coating) [(d)-(f)]. (a) Light microscopy image sequence of the $2 \mu \mathrm{m}$ ferromagnetic particle rotating synchronously in a 5 Hz external rotating magnetic field. (b) Characteristic rotational response for a $2 \mu \mathrm{m}$ ferromagnetic particle (experimental values are depicted by red circles), fitted to ferromagnetic particle rotational theory (black line) (c) DC SQUID characterization; typical ferromagnetic hysteresis is apparent with 75 Oe coercivity. (d) Characteristic rotational response for a $2 \mu \mathrm{m}$ SPM particles; behavior does not conform to the ferromagnetic theory. (e) DC SQUID characterization; hysteresis is not apparent, suggesting SPM behavior. (f) ZFC/FC curve; the blocking temperature, $T_{b}$, is approximately 120 K. Note: For SQUID hysteresis curves, the connected lines are used to aid in visualization; they do not represent a data fit. 
approximately 400 Oe, which may suggest a superparamagnetic contribution. ${ }^{25}$ Assuming no particle aggregation during the SQUID measurements, a $2 \mu \mathrm{m}$ ferromagnetic particle was calculated to have a magnetic moment of 5.22 $\times 10^{-14} \mathrm{Am}^{2}$ (Joules/Tesla), provided a saturation value of $1.4 \times 10^{-12} \mathrm{Am}^{2}$; this closely agrees with the magnetic moment value estimated by AMBR.

The magnetic properties of $2 \mu \mathrm{m}$ SPM particles were also investigated by AMBR and with a SQUID. The rotational behavior of the SPM particles does not agree with the ferromagnetic particle theory. ${ }^{14}$ This suggests a nonpermanent magnetic dipole origin of magnetic torque. Furthermore, only $10 \%$ to $15 \%$ of the particles were observed to rotate. We speculate that this could arise from the variability in thin-film nucleation during deposition. At frequencies between $100 \mathrm{~Hz}$ and $1 \mathrm{kHz}$, the $2 \mu \mathrm{m}$ SPM particles' rotational rates did not change significantly [see Fig. 3(d)]. This is a trait characteristic of an induced magnetic moment. ${ }^{26-28}$ From the SQUID analysis, coercivity in hysteresis loop measurements was not observed [Fig. 3(e)], which suggests that the particles are SPM. The SPM behavior was confirmed by the ZFC/FC curve [Fig. 3(f)], as the blocking temperature, $T_{b}$, is approximately $120 \mathrm{~K}$, a value well below our experimental conditions. ${ }^{29}$ We thus observed a transition from ferromagnetic to SPM behavior by reducing the Ni layer thickness on the $2 \mu \mathrm{m}$ particles from 60 to $5 \mathrm{~nm}$. This indicates that the magnetic behavior of Janus particles can be tuned by selecting desired values for the magnetic layer thickness.

To further demonstrate magnetic tunability, additional experiments were performed on $10 \mu \mathrm{m}$ ferromagnetic and $10 \mu \mathrm{m}$ SPM particles. The magnetic properties and uniformity of the $10 \mu \mathrm{m}$ ferromagnetic particles were characterized with a SQUID and by AMBR [see S.1 and S.2(a) and S.2(b)]. ${ }^{30}$ From SQUID measurements, the average magnetic moment of a $10 \mu \mathrm{m}$ ferromagnetic particle was calculated to be $4.22 \times 10^{-12} \mathrm{Am}^{2}$, which is consistent with the value calculated with AMBR, $(2.31 \pm 0.09) \times 10^{-12} \mathrm{Am}^{2}$. In addition, the $10 \mu \mathrm{m}$ ferromagnetic particles was calculated to have a $4 \% \mathrm{CV}$ in magnetic responsiveness. For comparison, commercially available $4 \mu \mathrm{m}$ carboxylated ferromagnetic particles (Spherotech, Illinois), as measured by AMBR, were calculated to have a $26 \% \mathrm{CV}$ in magnetic responsiveness. This level of non-uniformity is consistent with reported values. ${ }^{11}$ Furthermore, the $10 \mu \mathrm{m}$ SPM particles were characterized by AMBR, and their rotational response was found to behave similarly to the $2 \mu \mathrm{m}$ SPM particles [see S.2(c)]. ${ }^{30}$ Therefore, we have demonstrated that the magnetic behavior of the $10 \mu \mathrm{m}$ particles can be tuned by selectively choosing Ni thicknesses above and below the thin-film SPM limit. This further suggests that this tunability can be extended toward the fabrication of magnetically uniform ferromagnetic or SPM particles of other sizes.

In conclusion, we have fabricated Janus particles with greater particle-to-particle magnetic uniformity than those previously reported, by using a spin coating and thermal evaporation technique. This straightforward method allows the magnetic behavior and moment to be tuned by varying the particle size and/or the thickness of the magnetic deposition layer. Such uniform magnetic particles, when function- alized, may have significant utility in biomedical and biophysical applications.

This study was supported by Grant No. NSF/ DMR0455330 (R.K.) and NIH/UL1RR024986 (B.H.M.). B.H.M. and P.K. disclose financial interest in Life Magnetics, Inc. The authors would also like to acknowledge the University of Michigan's (UM) Lurie Nanofabrication Facility (LNF) and the UM Chemical Engineering Clean Room for use of fabrication equipment, as well as the UM Electron Microbeam Analysis Laboratory (EMAL) for SEM, and Dr. Reza Loloee at Michigan State University for SQUID magnetization measurements.

${ }^{1}$ Z. Saiyed, S. Telang, and C. Ramchand, Biomagn. Res. Technol. 1, 2 (2003)

${ }^{2}$ C. Chambon, O. Clement, A. Le Blanche, E. Schouman-Claeys, and G. Frija, Magn. Reson. Imaging 11, 509 (1993).

${ }^{3}$ J. Dobson, Drug Dev. Res. 67, 55 (2006).

${ }^{4}$ J. Ugelstad, P. C. Mørk, R. Schmid, T. Ellingsen, and A. Berge, Polym. Int. 30, 157 (1993).

${ }^{5}$ G. Korneva, H. Ye, Y. Gogotsi, D. Halverson, G. Friedman, J. Bradley, and K. G. Kornev, Nano Lett. 5, 879 (2005).

${ }^{6}$ M. Albrecht, G. Hu, I. L. Guhr, T. C. Ulbrich, J. Boneberg, P. Leiderer, and G. Schatz, Nature Mater. 4, 203 (2005).

${ }^{7}$ B.H. McNaughton, V.A. Stoica, J.N. Anker, K.M. Tyner, R. Clarke, and R. Kopelman, arXiv:cond-mat/0506418v1

${ }^{8}$ S. K. Smoukov, S. Gangwal, M. Marquez, and O. D. Velev, Soft Matter 5, 1285 (2009)

${ }^{9}$ K. Roh, M. Yoshida, and J. Lahann, Langmuir 23, 5683 (2007).

${ }^{10}$ K. P. Yuet, D. K. Hwang, R. Haghgooie, and P. S. Doyle, Langmuir 26 4281 (2010).

${ }^{11}$ U. O. Häfeli, M. A. Lobedann, J. Steingroewer, L. R. Moore, and J. Riffle, J. Magn. Magn. Mater. 293, 224 (2005).

${ }^{12}$ H. A. Ferreira, D. L. Graham, P. P. Freitas, and J. M. S. Cabral, J. Appl. Phys. 93, 7281 (2003).

${ }^{13}$ W. Shen, X. Liu, D. Mazumdar, and G. Xiao, Appl. Phys. Lett. 86, 253901 (2005).

${ }^{14}$ B. H. McNaughton, K. A. Kehbein, J. N. Anker, and R. Kopelman, J. Phys. Chem. B 110, 18958 (2006).

${ }^{15}$ B. H. McNaughton, R. R. Agayan, J. X. Wang, and R. Kopelman, Sens. Actuators B 121, 330 (2007).

${ }^{16}$ P. Kinnunen, I. Sinn, B. H. McNaughton, and R. Kopelman, Appl. Phys. Lett. 97, 223701 (2010).

${ }^{17}$ B. H. McNaughton, P. Kinnunen, R. G. Smith, S. N. Pei, R. Torres-Isea, R. Kopelman, and R. Clarke, J. Magn. Magn. Mater. 321, 1648 (2009).

${ }^{18}$ B. H. McNaughton, R. R. Agayan, R. Clarke, R. G. Smith, and R. Kopelman, Appl. Phys. Lett. 91, 224105 (2007).

${ }^{19}$ A. Hecht, P. Kinnunen, B. H. McNaughton, and R. Kopelman, J. Magn. Magn. Mater. 323, 272 (2011).

${ }^{20}$ P. Kinnunen, I. Sinn, B. H. McNaughton, D. W. Newton, M. A. Burns, and R. Kopelman, Biosens. Bioelectron. 26, 2751 (2011).

${ }^{21}$ V. M. Browning, Eur. Cells Mater 3, 5 (2002).

${ }^{22}$ S. Singamaneni and V. Bliznyuk, Appl. Phys. Lett. 87, 162511 (2005).

${ }^{23}$ H. Takei and N. Shimizu, Langmuir 13, 1865 (1997).

${ }^{24}$ A. Cēbers and M. Ozols, Phys. Rev. E 73, 021505 (2006).

${ }^{25}$ J. I. Hwang, M. Kobayashi, G. S. Song, A. Fujimori, A. Tanaka, Z. S. Yang, H. J. Lin, D. J. Huang, C. T. Chen, H. C. Jeon, and T. W. Kang, Appl. Phys. Lett. 91, 072507 (2007).

${ }^{26}$ P. Fannin, L. Cohen-Tannoudji, E. Bertrand, A. Giannitsis, C. Mac Oireachtaigh, and J. Bibette, J. Magn. Magn. Mater. 303, 147 (2006).

${ }^{27}$ X. J. A. Janssen, A. J. Schellekens, K. van Ommering, L. J. van IJzendoorn, and M. W. J. Prins, Biosens. Bioelectron. 24, 1937 (2009).

${ }^{28}$ S. L. Biswal and A. P. Gast, Phys. Rev. E 68, 021402 (2003).

${ }^{29}$ Y. Liu, D. Shindō, and D. J. Sellmyer, Handbook of Advanced Magnetic Materials (Springer Science + Business Media, New York, 2005).

${ }^{30}$ See supplementary material at http://dx.doi.org/10.1063/1.3541876 for further discussion. 